\title{
Positive Action Plans in Italian Universities: \\ Does Gender Really Matter?
}

By Giovanna Galizzi, University of Bergamo (Italy)

and Benedetta Siboni, University of Bologna - Campus of Forlì (Italy)

\section{DRAFT - The final version of this paper has been published as:}

G. Galizzi, B. Siboni (2016), Positive Action Plans in Italian Universities:

Does Gender Really Matter?, Meditari Accountancy Reserch, Vol. 24, No. 2, pp. 246/268

\begin{abstract}
Purpose - The European university context reveals a high degree of gender inequality. In Italy, the overall female employment rate is significantly lower than in the rest of Europe, nevertheless gender equality in universities is consistent with the European average. In 2006 the Italian Government required public organisations (thus state universities) to formulate positive action plans (PAPs) which disclose the positive actions planned for the following 3 years to promote gender equality. However, the law does not provide any guideline on the contents of the PAPs. The current paper analyses gender equality disclosure in PAPs in order to investigate whether and how Italian State Universities (ISUs) are taking a role in promoting gender equality.
\end{abstract}

Methodology - The paper uses content analysis to investigate contents of gender disclosure in 28 PAPs. A coding instrument based on the Guidelines for Gender Equality Programmes in Science was developed by the authors.

Originality/value - First, the paper contributes to the accounting literature by providing an analysis of accounting for gender by universities. Second, it adds to the debate on positive actions for gender equality in the university sector.

Findings - The paper found that most PAPs are focused on creating a favorable environment for women inside the organisation, while little attention has been paid to creating gender awareness in research and teaching activities, as well as in supporting women's leadership. The paper concludes that ISUs are failing as key players in the cultural change of society towards gender equality.

Keywords - Accounting, Gender, Universities, Positive Action Plans, Content Analysis

Paper type - Research Paper 


\section{Introduction}

Traditionally, accounting has been considered to be gender neutral because of its rationality and objectivity. Therefore, for a long time no studies investigated accounting practices through the lens of gender. Since the 1990s some researches have been published with regards to gender accounting, but with hardly no reference to the planning phase (Parker, 2008). Such studies accuse accounting professions of being male[1] dominant, because of a number of gender stereotypes resulting in an under-representation of women (e.g., Lehman, 1992). Moreover, they support the idea that the nature of accounting practices represents masculine values, inhibiting feminine qualities. Nowadays, because of the wider interaction between males and females in accounting professions, traditional accounting frameworks need to be rethought (e.g., Broadbent, 1998).

University has been considered to be a sector in which merit should prevail and therefore be gender neutral. Recent reports, however, denounce the under-representation of women in universities all over the world (UN, 2010; Unesco, 2012) and specifically within the European context (e.g. EU, $2012 \mathrm{a}, 2012 \mathrm{~b}, 2012 \mathrm{c})$. One of the main features of the contemporary university system concerns the increase in women's education with females normally performing better than males (EU, 2008), yet in most countries women's careers remain markedly characterised by a strong vertical and horizontal segregation[2]. The current under-representation of women results in a waste of female talent and, thus, prevents the achievement of the European Research Area's objective of Excellence in Research (EU, 2012d). To counter this phenomenon, the European Union has engaged in several initiatives that encourage universities to adopt positive actions. Positive actions include measures targeting the special needs of women in order to overcome their position of inequality (Rees, 2007). Furthermore, several guidelines have been issued to support the dissemination of positive actions by European universities (Prages, 2009; GenSet, 2010; EU, 2012c), considering such institutions as main players for the cultural change of society.

According to Eurostat (2013) in Italy there is a strong inequality picture in the labour participation compared to the European average. In fact, the employment rate for women is $49.9 \%$ (against $62.6 \%$ ), while the one for men scores at $69.8 \%$ (against $74.4 \%$ ). At the same time, with reference to academia, the Italian women's participation rate is consistent with the European average, that accounts for $34 \%$ against $66 \%$ of that of men (Unesco, 2012). This makes it interesting to investigate both how Italian Government and ISUs themselves have supported female labour participation in universities. The current research could provide other countries and universities with some insight on how to encourage gender equality.

Since 2006, Italian public organisations have been required to formulate Positive Action Plans (PAPs) to promote gender equality at the workplace. According to the Italian legislative framework, the planning phase is the one that drives the overall public management; thus, public organisations cannot undertake any action if it has not been preliminarily planned. However, no specific guidelines on the contents of PAPs have been provided by the Law; consequently, each organisation can choose which positive actions to include.

The accounting literature produced so far has focused mostly on women conceived as individuals, while little attention has been paid on investigating the actions that organisations could adopt to promote gender equality. Moreover, very few studies have investigated positive actions (Rittenhofer, Gatrel, 2012), and to our knowledge there are no researches exploring positive actions with regard to Italian universities. To bridge this gap, the current paper aims to analyse gender disclosure included in the PAPs issued by Italian State Universities (ISUs), in order to investigate whether and how they are taking a role in promoting gender equality for the cultural change of society. In particular, the paper focuses on recommendations planned by ISUs, while it does not investigate the adoption of such recommendations nor their impact.

Accordingly, the paper answers the following questions:

- What is the incidence and frequency of gender recommendations?

- What is the quality of gender recommendations?

- Who are the stakeholder groups to whom gender recommendations are addressed? 
Content analysis has been used to analyse recommendations planned by 28 ISUs in their PAPs. To that end, an original coding instrument was developed on the basis of the Guidelines for Gender Equality Programmes in Science (Prages, 2009).

The paper found that ISUs' PAPs do focus on gender issues. However, they focus mainly on creating a favourable environment for women, while little attention has been paid to creating gender awareness in research and teaching activities and to support women's leadership. With regard to the quality of disclosure, very little attention has been paid to monetary information; this could jeopardize the future implementation of the positive actions planned. As far as stakeholder groups are concerned, positive actions have been targeted mainly towards academics and administrative staff. The paper concludes that currently ISUs are failing in playing a role of key actors in driving the cultural change of society towards gender equality. In fact, the planning of positive actions is still at an initial stage and it mainly involves structural factors, rather than factors leading to the cultural change of researchers and students as well as of governing bodies.

The current paper is located within the accounting literature with a particular focus on the planning. By providing an analysis of PAPs, it seeks to contribute to the debate on "accounting for gender" on the part of universities. Moreover, the paper intends to suggest some key recommendations universities should plan in order to promote gender equality. Finally, the paper aims to stimulate the accounting debate on gender equality, by providing a "gender agenda" for future research.

The paper proceeds as follows. Section 2 gives the theoretical background of the paper by reviewing the literature on gender in accounting. Section 3 provides data on gender representation in universities. Section 4 examines the guidelines for gender equality in universities. Section 5 illustrates the research method. Section 6 reports on the results of the analysis. Section 7 presents the conclusion and proposes a gender agenda for the future.

\section{Literature Review}

The literature on gender has developed since the 1970s, receiving massive coverage in both feminist theories as well as in philosophical and historical writings (Lehman, 2012). Since the 1990s some special issues on gender have been published by the main managerial and accounting journals (Accounting, Accountability \& Auditing Journal, 1992, 2008; Accounting, Organizations and Society, 1992; Critical Perspectives on Accounting, 1998; Academy of Management Journal, 2015). Also, the gender agenda has been identified as one of the areas in which accounting academics should engage more in the future (Samkin, Schneider, 2014a; Broadbent, 2015; Parker, 2015).

Four mainstreams could be found on gender research in accounting. First, a number of studies have focused on women's entry and on their empowerment within accounting professions (Lehamn, 1992; Kirkham and Loft, 1993). On the one hand, some works describe the increasing presence of women in male-dominated accounting professions since the 1970s and denounce the current persistence of the "glass ceiling" (Dambrin, Lambert, 2008; Weir et al., 2014) and "horizontal segregation" phenomena, with women typically relegated to white-collar jobs (Lehman, 1992; Thane, 1992). On the other hand, several studies provide storytelling to account for the difficulties and the forms of exclusion that women typically face in accounting professions (e.g. Broadbent, Kirkham, 2008; Dillard and Reynolds, 2008; Komori, 2008). Second, several works have dealt with the scarcity of women in the highest levels of accountancy (e.g. Barker, Monks, 1998; Ciancanelli et al., 1990; Hooks, 1992). In such a context, Dambrin and Lambert (2012) question the academic discourse produced so far, which pretends to be neutral while "adopting an illusory position which is detrimental to the situation of women" (p. 1). Third, a small amount of research has investigated the relationship between gender and ethnicity, giving evidence for the difficulties faced by nonCaucasic women in accounting professions (e.g., McNicholas et al.; 2004; Kim, 2004). Accordingly, Dambrin and Lambert (2008), Komori (2008) and Walker (2008) observed that previous studies focused only on Anglo-Saxon countries, hence further research has to be undertaken with reference to different geographical areas, in order to provide a broader spectrum of 
knowledge. Fourth, little literature has focused on the issue of gender and academia. On the one hand, such research has highlighted the under-representation of women and explored the discriminations faced by female scholars (e.g. Haynes and Fearfull, 2008; Dambrin and Lambert, 2012). On the other hand, some studies have analysed the outputs of research undertaken by women, highlighting that accounting is a discipline more masculine (Walker, 2008), because of the low number of females working in academia. Nonetheless, Samkin and Schneider (2014b) found that in New Zealand female senior lecturers were more productive than their male counterparts.

Since 2000s, several studies have investigated the reasons for gender inequality at universities. Nowonty et al. (2001) highlighted the risk of women not concretely achieving equality and the risk society is taking in wasting women's talents. According to Prages (2009), universities are affected by a hidden structure of discrimination. Since the university sector is considered to be perfectly objective and meritocratic, it is taken for granted that it can disregard the gender issue. However, a series of invisible segregating mechanisms, which often go unrecognised even by women themselves, arise from this assumption of gender-blindness. Accordingly, Best et al. (2013), Prages (2009), Tan et al. (2011), identified three main areas of stereotypes that prevent women from devoting themselves to research:

- the dominant understanding and practice of research which is normally gendered as masculine;

- the fact that some features of Science, Technology, Engineering and Mathematics (STEM) do not appeal to the general female population;

- the male-dominated dynamics of leadership and consequently a lack of female role models in academia.

From the review undertaken it emerges that the literature (particularly the accounting one) has focused mostly on women conceived as individuals, whereas there is a lack of research with reference to organisations and their commitment to address the gender equality issue. However, with reference to the university context the European Union calls to move from the investigation of women scholars to the organisations that employ them, with the aim to undertake a structural change towards gender equality (EU, 2012c). According to Sinnes (2006), there are three main theoretical approaches universities could adopt to take gender into account. First of all, the genderneutral approach starts from the assumption that men and women have an equal ability to research, therefore gender does not affect the intellectual ability of producing knowledge. Thus, the differences between men and women in universities arise from the differences in their training. According to this approach, inequality in universities is caused by factors that are external to research, therefore positive actions should focus on removing these external obstacles. Second, the women-friendly approach is based on the assumption that the identity of a researcher influences the development of the research and it is a historical fact that the development of knowledge has so far been dominated by men and western culture. Women have better qualities than men, due to their underprivileged position that has led them to implement different abilities in order to achieve success in the workplace. Consequently, universities should formulate positive actions that acknowledge the differences between males and females, designing a female-friendly environment. Third, the gender-sensitive approach is based on the assumption that neither men nor women are able to take each other's place in describing the world. Thus, universities should promote positive actions that highlight differences between men and women, as well as encourage the recruitment of women because of their own perspectives, approaches and stories that would be lost without their contribution.

The above literature review highlights that little research has been performed on the topic of gender in accounting with particular reference to academia, resulting in a call for research in this field (e.g. Broadbent, Kirkham, 2008; Dambrin and Lambert, 2012). Also, according to Parker (2008) gender research in accounting has so far mostly been focused upon structural factors rather than upon management and accounting actions and processes, and the issues of strategic management and accounting have remained sadly neglected. Accordingly, Walker (2008) observed that future research in accounting should move away from the current focus towards the study of positive 
actions that organisations should plan to deal with the gender inequality issue. To contribute to bridging this gap, the current paper provides an analysis of positive actions planned by ISUs.

\section{The University Context}

Despite the increasing feminisation of workplaces worldwide, since 2006 an increasing gender gap has been highlighted. However, the gender gap situation varies widely between countries; for instancethe women employment rate accounts for $82 \%$ in Iceland while it is just $26 \%$ in Yemen (WEF, 2014). With regards to Europe it stands on average at $62.6 \%$, varying from the northern countries $(71 \%)$ to the southern ones $(53 \%)$. With regards to the university sector, women account for a minority of the world's scholars, scoring on average at $45.2 \%$ in Latin America and the Caribbean, at $39.2 \%$ in Oceania, at $34.5 \%$ in Africa, at $34 \%$ in Europe, and at $18.9 \%$ in Asia, while no data are available for North America (Unesco, 2012). Similarly, the number of women in academia varies widely between European countries (Oecd, 2015), showing higher rates in Romania (46.5\%), Estonia (43.7\%) and the Slovak Republic (42.6\%), and lower rates in France (25.6\%), the Netherlands (24.2\%) and Luxembourg (24\%).

Drawing from the gender inequality situation that women have historically suffered in the workplace (Rees, 2007), since the early 1970s the European Union has encouraged member states to adopt positive actions in order to improve the situation of women in society (for instance, Directive 1976/207, European Recommendation 1984/635). Directive 2006/54 states that public sector organisations must "lead by example" for the private sector in adopting positive actions devoted to the promotion and implementation of gender equality. In addition, since the late 1990s, the European Union has committed itself to the promotion of gender equality in universities in order to counter the waste of women's skills and knowledge, to fight the "leaky pipeline" phenomenon[3], as well as to make universities the main players for the cultural change of society towards gender equality. In such a context, an equal participation of women and men in university has been considered a key condition for the construction of the European Research Area of Excellence in Research (EU, 2002, EU, 2012d). To support that end, the European Union has engaged in several initiatives. First of all, in February 1999, it set out the Women and Science[4] Action Plan aimed at mobilising women to enrich European research. Then, in May 1999, the Research Council adopted a Resolution on Women and Science inviting member states to exchange views on national policies, benchmarking and best practices for gender equality. Moreover, it invited member states to establish baseline data and procedures for data collection on gender with reference to the university sector, as well as to develop indicators to measure the participation of women in research. After that, in November 1999 the European Union established a permanent Group (known as the Helsinki Group), commissioned to the promotion and exchange of national experiences on gender measures and policies in research.

Since 2002, the Helsinki Group has produced a report called "She Figures" that provides data and indicators on women's representation in universities, with the aim of monitoring the impact of gender measures adopted by each member state. In the latest She Figures report available (EU, 2012a), it emerges that the European average picture still shows a strong situation of gender inequality. Although females represent most of the population of students and graduates, at the first grade of a typical academic career the share of females falls below that of men (standing respectively at $46 \%$ and $54 \%$ ), even dropping to $20 \%$ at the top of ladder. Furthermore, in the STEM fields the share of females is much lower at all levels, accounting for just $11 \%$ of academic staff. Finally, in terms of roles in decision-making bodies the unbalanced representation of women persists, with only 1 woman for every 2 men on management boards, whilst women represent only the $10 \%$ of university Rectors.

Looking at the data reported above, it emerges that there are countries with an overall higher female employment rate which present, at the same time, lower female employment rates with regards to academia. On the contrary, most countries with overall lower female employment rates present a 
higher female employment rates with regards to academia. Accordingly, in Italy the overall female employment rate scores at $49.9 \%^{1}$ against the European average rate of $62.6 \%$, while the number of those working in academia is in line with the European average, standing at 34\%. Furthermore, in Italy, despite the fact that the number of female students, graduates, and Ph.Ds. has recently increased, the proportion of women falls drastically when we move from the early career stage to the top positions. In fact, the share of women assistant professors is $46 \%$, associated professors $35 \%$ and full professors $21 \%$, demonstrating the persistence of a leaky pipeline phenomenon. Similarly, at the top of the administrative staff the share of female managers stands at $37 \%$, while at the other levels women staff represents 58\% (Miur, 2015). With regard to governance bodies, the number of women is still very low standing at $17 \%$, and just $5 \%$ of Rectors are female (Vagnoni et al., 2014). The university sector in Italy is regulated by the Ministry of Education, University and Research[5] (Miur). It consists of 66 state universities and 30 non-state universities (Cineca, 2015). Students enrolled in ISUs represent $91 \%$ of the overall Italian university population. Like in other European countries, since the 1990s the Italian university system has undergone a season of reforms led by the New Public Management approach. With regard to the gender issue, the reforms have focused on the steering mechanisms used for achieving gender equality. Drawing from that, Müller et al. (2011, p. 303) has observed that similarly to other European countries, currently in Italy "several policy instruments such as legal/rights measures, positive actions (such as quotas), co-exist alongside more recent 'mainstreaming' mechanisms and new steering instruments such as target/incentive-bound resource allocation". In particular, positive actions were introduced by Italian Law no. 125/1991. Furthermore, Decrees no. 198/2006 and no. 5/2010 (referring to the European Directive 2006/54) provide that every public organisation (thus state universities) has to prepare a "PAP". PAPs are documents in which organisations disclose the positive actions planned for the following 3 years to promote gender equality, together with monetary and human resources devoted to achieve such positive actions. However, the regulation only gives very general indications saying that PAPs have to include positive actions aimed at removing barriers that prevent the realisation of equal opportunities, promoting women's employment, achieving substantive equality between men and women, as well as improving the overall well-being at work. Nevertheless, no specific guidelines have been given with regard to the contents of PAPs. Consequently, each public organisation has freedom of choice on which positive actions to plan.

\section{Guidelines for Gender Equality in Universities}

Since the late 1990s, several guidelines have been financed by the European Union to encourage universities to formulate positive actions (Prages, 2009; genSET, 2010; EU, 2012c). A review of the main features of these guidelines is provided below.

\section{Practising Gender Equality in Science (Prages)}

Prages (2009) was developed by a group of experts from Italy, the United Kingdom, Hungary, Denmark, Australia and the United States. The guideline was formulated on the basis of an assessment of 109 gender equality programmes issued by universities, scientific institutes, women's networks and associations, as well as enterprises belonging to the scientific and technological fields. Prages (2009) proposes the dissemination of three strategies devoted to gender equality in universities. The strategies are: A - "A friendly environment for women", which involves the preliminary conditions allowing the pursuit of a more favorable environment for women; $\mathrm{B}$ "Gender-aware science", that addresses the issue of the stereotyped image of research as masculine. C - "Women's leadership of science in a changing society", which focuses on attaining gender balance in leading positions. Those strategies are developed further via objectives (no. 9), recommendations (no. 31) and lines of action (no. 61).

\footnotetext{
${ }^{1}$ Only Malta and Greece show lower rates than Italy, with respectively 49,8\% and 43,3\% female employment rate.
} 
Recommendations for Action on the Gender Dimension in Science (genSET)

GenSET (2010) was developed by a network consisting of experts from several European universities, the Quality Agency of the Spanish National Health System, the Italian National Research Council, the academic journal "Lancet", and Unilever Ltd, which worked together with science stakeholder institutions, gender experts and science strategy decision-makers.

The guideline encourages universities to adopt Gender Action Plans to increase women's participation in the workplace. GenSet (2010) lists 5 key areas where the participation of women usually finds biases: the making of science knowledge, the research process, recruitment and retention, the assessment of women's work, the evaluation system of excellence in science. The guideline suggests 13 recommendations that provide universities with practical ways to include the gender dimension in their decision making.

Structural Change in Research Institutions: Enhancing Excellence, Gender Equality and Efficiency in Research and Innovation (EU)

EU (2012c) was formulated by a group of experts appointed by the European Commission with the aim of understanding the full gender equality picture in the European research context.

The guideline suggests that universities have to undertake a "structural change" in order to face the current situation of gender inequality. This change involves 5 mainstreams: rendering decisionmaking transparent, removing the unconscious bias from institutional practices, promoting excellence through diversity, improving research by integrating a gender perspective, and modernising the management of human resources and the work environment. A group of 19 suggested measures should be presented in order to improve gender equality within each mainstream.

From the analysis of the above guidelines it is clear that all of them encourage universities to adopt positive actions to foster gender equality. In addition, all the guidelines are the result of the exchange of experiences between universities and gender experts from different countries. While genSET (2010) and EU (2012c) give a few general recommendations, Prages (2009) provides a number of detailed recommendations, based on the widest group of experiences analysed (109 in total). To sum up, Prages (2009) appears to be the most appropriate guideline to perform the analysis of ISUs' PAPs for a number of reasons. First of all, it gives a detailed list of recommendations that are likely to provide a comprehensive representation of positive actions in universities. Furthermore, it provides a clear definition and examples for each recommendation, facilitating the classification of each piece of information recorded by the analysis. Finally, Prages (2009) is the result of the analysis of a large number of universities from all over the world, including evidence from Australia and Canada where there is a high level of attention to gender issues.

\section{Research Method}

With the aim of analysing disclosure within ISUs' PAPs, Content Analysis (CA) has been performed. According to Berelson (1952), CA is a technique that describes in an objective, systematic and quantitative way the content of communication. CA has become the dominant method for analysing social and environmental information in accounting (Parker, 2005), and it has been widely applied to the study of sustainability disclosure by organisations (e.g. Guthrie, Abeysekera, 2006; Parker, 2005). Given that the gender issue belongs to the field of social issues (e.g. GRI, 2013), in this paper CA was chosen as a method for investigating gender disclosure in ISUs' PAPs.

CA implies the use of a coding instrument, that is an instrument which lists pre-defined categories and sub-categories of information to organise the data and findings. Within the coding instrument, 
the presence of a certain sub-category of information disclosed is recorded. Typically, the more frequently disclosure is found, the more important the sub-category is considered to be (Beck et al., 2002). In addition, CA often implies computing a disclosure index. It provides an aggregate measure of the quantity of disclosure within the documents analysed (e.g. Guthrie, Abeysekera, 2006; Siboni et al., 2013). The coding instrument used to perform CA in this paper was developed by the authors on the basis of Prages (2009). It is arranged in a hierarchy of items that are: strategies (no. 3), objectives (no. 9), recommendations (no. 31) and lines of action (no. 61). The strategies refer to the key issues that are the basis of the multiple obstacles that women usually have to deal with. The objectives refer to measures that universities should undertake to achieve gender equality with reference to each strategy. The recommendations relate to aspects that have to be addressed by universities because they influence the achievement of each objective. Finally, the lines of action relate to practical measures that universities have to undertake to put each recommendation into practice.

In the current research, CA was manually developed using Excel to record disclosure in specific worksheets shaped on the basis of the coding instrument. The CA has recorded the incidence and frequency of gender disclosure in PAPs by adopting the "phrase" as a unit of analysis of the texts. The phrase has been chosen because from a preliminary examination of PAPs it appeared to be the most suitable unit for the analysis. In particular, the CA recorded "1" when the unit of analysis was found in the text and " 0 " if it was not. No visuals were found in PAPs. Furthermore, the CA recorded the quality of gender disclosure on the basis of a four-scale range that is well established in accounting literature (Guthrie et al., 2004), identifying declarative, monetary, non-monetary, monetary and non-monetary information. This scale was relevant to the analysis of PAPs because according to the New Public Management approach plans have to disclose actions to be undertaken as well as targets, human and monetary resources devoted to their achievement, and timing. Finally, CA recorded the stakeholder groups to which gender disclosure has been addressed. Stakeholder groups have been classified under four categories (EU, 2012a): Academics, Researchers in Training (including fellowship researchers, Ph.Ds and Ph.D. students), Administrative Staff, Students, Others. Zero (0) indicates information that was not declared.

To strengthen the reliability of CA we made the following choices (Guthrie et al., 2004). First, we developed an original coding instrument on the basis of a well-grounded relevant document (Prages, 2009), resulting in shared meanings of recommendations to be analysed, that allow the research to be repeated. Second, we established precise rules for examining the PAPs and defined specific strategies, objectives, recommendations and lines of action for classifying any piece of information recorded. Third, the coder who performed the analysis is an expert on gender issues and was trained on CA by the second author who is an expert on such a method; the coder then had sufficient time to become confident with the coding instrument. Finally, to limit the intrinsic subjectivity of the coding process, the second author undertook a reliability test on a previous sample of PAPs analysed by the first author, which resulted in no major differences in codification. Also, during the analysis there was a continuous exchange of views between the coder and the second author on how to codify pieces of information whose attribution could have been equivocal.

Out of the 66 ISUs 28 ISUs' PAPs were found, representing $42 \%$ of the ISUs and $41 \%$ of the overall Italian student population. This was done by checking all the ISUs' websites during the December 2014 - January 2015 period. Surprisingly, despite the fact the Italian regulations require ISUs to publish PAPs, not all universities have done it yet, or at least not all of them have put PAPs on their website. Where more than one PAP was found for a single ISU, the most recent one was examined. 


\section{Results of the analysis}

Table I shows the incidence of each strategy of Prages (2009) disclosed by ISUs' PAPs. The incidence was computed on the basis of the total observations[6] from the 28 plans out of the total possible observations. The first column shows the strategies and the second column the number of objectives according to Prages (2009), while the third column discloses the number of observations of each objective in the plans analysed. Finally, the fourth column displays the total index that gives the percentage of objectives of the coding instrument disclosed within the plans. Out of the total of 252 objectives that could have been observed from the 28 PAPs, only 124 were disclosed, that means $49 \%$ of the total possible disclosure.

\section{[Insert Table I Here]}

As shown in Table I, all the Prages (2009) strategies were disclosed. The most disclosed Strategy is A - A friendly environment for women $(71 \%)$ followed by B - Gender-aware science and C Women's leadership of science in a changing society (38\% each). This suggests that ISUs focus mostly on the strategy aimed at removing structural barriers for women in the workplace. Positive actions included in this frame aim at establishing gender disaggregated data measurement systems (on employees, training, wages, research outputs and funds, etc.), as well as at developing specific information tools devoted to gender issues (web pages on gender, online FAQ, etc.), and at creating in-house services and policies to support women (kindergartens, flexibility and part-time work, etc.). At the same time, little attention has been paid on the strategy aimed at challenging gender stereotypes in teaching and in research activities, as well at incorporating the gender dimension in scientific contents and methods. Positive actions in this frame should include grants awarded to female students who enroll in STEM degrees, as well as actions aimed at raising awareness of the advantages connected to gender medicine, etc. Another aspect to be largely neglected has been the strategy focused on encouraging female leadership; this strategy should bring on positive actions aimed at defining a gender quota system for appointing boards and committees, as well as strengthening the image of successful female role models.

Table II illustrates the frequency of disclosure by ISUs' PAPs on the basis of Prages (2009). The first column shows strategies. The second and third columns illustrate objectives and recommendations. The fourth and fifth columns present the sum of the recommendations disclosed in absolute value as well as in percentage value.

\section{[Insert Table II Here]}

As shown in Table II, the most cited strategy is A - A friendly environment for women (67.1\%), followed by strategy C - Women's leadership of science in a changing society (18.6\%), and strategy B - Gender-aware science (14.3\%). With regard to recommendations, out of the 31 recommendations only 4 were not cited, therefore we can infer that $87 \%$ of the recommendations were cited at least once. All the 4 recommendations that received 0 citations belong to strategy $\mathrm{C}-$ Women's leadership of science in a changing society. This means that no ISUs have ever included in their PAPs recommendations aimed to: facilitate the creation of relationships between women and social actors; promote new research environments linking innovation and gender diversity; promote mobility schemes allowing women scientists to gain experience in innovation; support women's applications for boards and commissions; modify rules and procedures for appointing boards and committee members with quota systems; develop training and awareness-raising initiatives addressing female leadership).

The frequency of recommendations cited varies from $26.8 \%$, to $0.1 \%$, with only 3 recommendations having a frequency higher than $10 \%$. These are: A.1.3. - Keeping women's issues in the foreground (26.8\%), including the development of communication tools on gender issues, A.2.1. - Creating a network of services (13.1\%), including the establishment of new in-house services targeted at 
women and at promoting flexible working hours and tele-working, and A.1.1. - Documenting gender discrimination (12.3\%), for instance though surveys submitted to employees. All three of these recommendations belong to strategy A - A friendly environment for women. These figures indicate that ISUs' have decided to concentrate their positive actions on a narrow range of recommendations to support gender equality. Moreover, these data reinforce the argument that ISUs mostly focus their positive actions on structural factors that have to do with changing the working environment rather than encouraging a change in the culture of the university by helping women get leading positions and increasing women's representation in decision-making bodies.

Table III provides some examples of recommendations extracted from PAPs analysed for each objective.

\section{[Insert Table III Here]}

Table IV reports on the quality of gender disclosure. The first column shows the four-range scale used to account for the quality of information; the second and third columns give the absolute values as well as the percentages of gender information disclosed.

\section{[Insert Table IV Here]}

As emerges from Table VI, disclosure in PAPs is mainly declarative (70\%), followed by nonmonetary $(27 \%)$, and monetary and non-monetary $(3 \%)$. Indeed, this scarcity of monetary information could affect the reliability of the positive actions as well as the effectiveness of PAPs' in acting as a tool of the organisation's planning process.

Finally, Table V reports on the stakeholder groups to whom recommendations are addressed. The first column shows the groups of stakeholders (EU, 2012a); the second and third columns give the absolute values as well as related percentages.

\section{[Insert Table V Here]}

As emerges from Table $\mathrm{V}$, the positive actions planned by ISUs are mainly addressed to both administrative $(31 \%)$ and academic $(27 \%)$ staff, while less attention has been paid to students $(17 \%)$ and researchers in training (9\%). Only $3 \%$ of positive actions were addressed to others, meaning categories of people from outside the university itself $(3 \%)$. Surprisingly, the positive actions planned by ISUs give little attention to young generations (students and researchers in training) who are, on the contrary, those who are more capable of impacting on the cultural change of society. Notably, for $13 \%$ of the positive actions the stakeholder groups remain undeclared; this absence of information highlights the risk of generality that may affect the positive actions as well as their achievement.

\section{Conclusions}

Since the end of the 1990s the European Union has promoted several initiatives to foster women's representation in universities in order to fight the waste of female talents, as well as to promote excellence in research. However, the current European university context highlights a strong underrepresentation of women, where they account just for the $34 \%$ of total academic staff.

Overall, Italy shows a significant inequality picture in female employment rates compared to other European countries (Eurostat, 2013), even though it scores on the European average with reference to the university sector. This makes it interesting to investigate both how the Italian Government and ISUs themselves have supported female labour participation in universities. 
In 2006, the Italian Government required public organisations to issue PAPs which disclose the positive actions planned. Nevertheless, no guidelines have since been provided on the contents of positive actions to formulate.

This paper analysed gender disclosure in ISUs' PAPs in order to investigate whether and how universities have promoted gender equality.

The paper found 28 ISUs that have issued a PAP, whom were mostly at the first attempt of formulating the document. Also, it was found that ISUs' PAPs do have a focus on gender disclosure. They predominantly focus on positive actions aimed at implementing structural factors to create a friendly environment for women, through measures aimed to disseminate information on discrimination, to collect disaggregated gender data as well as to establish a network of services that deal with maternity and childcare. Nevertheless, little attention has been paid on positive actions aimed at creating a gender-aware science and at fostering women's leadership in academia. Coherently, the positive actions disclosed were mainly addressed to administrative staff and academics, while less attention has been paid to both researchers in training and students, which are, on the contrary, those who are most able to impact on the cultural change of society. In contrast, according to the institutional mission of universities, one would expect them to promote positive actions focused on making a broader impact on society towards gender equality. Such impact would be achieved via an approach integrating the gender dimension in the overall mission, by changing the research and teaching schemes according to female characteristics, supporting the leadership of women in academic environments and promoting gender discourse in the relationships with the territory.

The current paper, by providing an analysis of PAPs seeks to contribute to the debate on "accounting for gender" on the part of organisations. It concludes that in Italy the regulations have compelled ISUs to adopt gender strategies via PAPs, but the country has failed in promoting ISUs formulate positive actions related to their overall mission; in so doing ISUs are failing to act as key players in the cultural change of society. The lack of a legislative framework on the contents of PAPs brought ISUs to focus only on the internal dimension, just like any other organisation. This paper suggests the European Union should issue a specific recommendation that lists positive actions to be undertaken by universities. Such a recommendation should stress the adoption of positive actions focused on encouraging women's leadership and careers in academia, as well as at supporting the gendering of research and teaching. In this context, some positive actions to be adopted could be: supporting female early-career researchers and their advancement; students' counselling to make enrollment choices free from gender stereotypes; incorporating gender issue in Ph.D. programmes to stimulate a gender-sensitive research.

Moreover, the current paper provides a foundation for a future "gender agenda" in accounting research. Future works could:

- update the current study to investigate if there are any changes in term of the disclosure of positive actions, from the first PAPs to further editions. This could highlight if there is an "ongoing learning approach" in terms of gender within ISUs;

- analyse the adoption of "positive actions implemented" by universities as well as the impact produced by these actions. These studies will give indications on what is actually happening in those organisations and on the levels of change in terms of gender equality induced by positive actions;

- interview stakeholder groups to whom positive actions are addressed in order to explore their "perception on gender issues" as well as to investigate the extent to which the positive actions implemented by ISUs have addressed their needs.

\section{Notes}

1. According to the relevant literature (EU, 2012a), in the current paper man/men and male/males are considered synonyms and the same applies to woman/women and female/females. 
2. "Gender segregation refers to a situation where women and men are unequally distributed across sectors of economic activity (horizontal segregation) or across occupational categories (vertical segregation). When interested in gender segregation in science, horizontal segregation refers to an unequal distribution of women and men across scientific fields." (EU, 2012a, p. 76).

3. The "leaky pipeline" phenomenon in research refers to "the situation where women begin scientific careers, indeed they may even be the majority of graduates in some scientific disciplines, but they then disappear in disproportionate numbers at each stage of the academic ladder" (EU, 2002, pp. 15-16).

4. According to the Recommendation Concerning the International Standardisation of Statistics on Science and Technology (Unesco, 1978), six major fields of science and technology exist: Natural Science; Engineering and Technology; Medical Science; Agricultural Science; Social Science; Humanities. In most countries, accounting belongs to the Social Science field.

5. According to the classification by Miur, the 66 state universities include schools of graduate studies, training institutes for Ph.D. programmes, and universities for foreign students.

6. The number of observations is given by the total number of times in which each objective was cited at least once in all the 28 PAPs.

\section{References}

Barker, P.C. and Monks, K. (1998), "Irish women accountants and career progression: a research note”, Accounting, Organizations and Society, Vol. 23 No. 8, pp. 813-823.

Beck, C., Campbell, D. and Shrives, P. (2002), "Content analysis in environmental reporting research: enrichment and rehearsal of the method in a British-German context", The British Accounting Review, Vol. 42 No. 3, pp. 207-222.

Berelson, B. (1952), Content analysis in communication research, The Free Press of Glencoe, New York, NY.

Best, K L., Sanwald, U., Ihsen, S. and Ittel, A. (2013), "Gender and STEM in Germany: policies enhancing women's participation in academia", International Journal of Gender, Science and Technology, Vol. 5 No 3, pp. 292-304.

Broadbent, J. (1998), "The gendered nature of 'accounting logic': pointers to an accounting that encompasses multiple values", Critical Perspectives on Accounting, Vol. 9 No. 3, pp. 267-297.

Broadbent, J. (2015), “A gender Agenda", paper presented at the SIDREA International Workshop Mediari Accountancy Research European Conference 2015, University of Bologna, School of Economics, Management and Statistics, Forli Campus, Italy.

Broadbent, J. and Kirkham, L. (2008), "Glass ceilings, glass cliffs or new worlds?: Revisiting gender and accounting", Accounting, Auditing \& Accountability Journal, Vol. 21 No. 4, pp. 465-473.

Ciancanelli, P., Gallhofer, S., Humphrey, C., Kirkham, L. (1990), “Gender and accountancy: some evidence from the UK", Critical Perspectives on Accounting, Vol. 1 No. 2, pp. 117-144.

Cineca (2015), “Cerca Università”, available at: http://cercauniversita.cineca.it/ (accessed 15 march 2015).

Dambrin, C. and Lambert, C. (2008), "Mothering or auditing? The case of two Big Four in France", Accounting, Auditing \& Accountability Journal, Vol. 21 No. 4, pp. 474-506.

Dambrin, C. and Lambert, C. (2012), "Who is she and who are we? A reflexive journey in research into the rarity of women in the highest ranks of accountancy", Critical Perspectives in Accounting, Vol. 23, pp. 1-16. 
Dillard, J. and Reynolds, M. (2008), "Green owl and the corn maiden", Accounting, Auditing \& Accountability Journal, Vol. 21 No. 4, pp. 556-579.

EU (2002), "National policies on women and science in Europe", Helsinki group on women and science, European Commission.

EU (2008), "The life of women and men in Europe - A statistical portrait", Eurostat Statistical books, European Commission.

EU (2012a), "She Figures 2012. Gender in research and innovation. Statistics and indicators", European Commission.

EU (2012b), "Meta-analysis of gender and science research”, European Commission.

EU (2012c), "Structural change in research institutions: enhancing excellence, gender equality and efficiency in research and innovation", European Commission.

EU (2012d), "Communication from the Commission to the European Parliament, the Council, the European economic and social committee and the Committee of the regions. A reinforced European Research Area partnership for excellence and growth", European Commission.

Eurostat (2013), "Oltre la conciliazione, prospettiva produttività. Mercato del lavoro - Tasso di occupazione", available at: http://www.italialavoro.it/ (accessed 21 November 2015).

GenSET (2010), "Recommendations for action on the gender dimension in science", available at: http://www.genderinscience.org/ (accessed 29 January 2015).

Globlar Reporting Initiative (2011), G4 Sustainability Reporting Guidelines, available at: https://www.globalreporting.org/ (accessed 23 December 2015).

Guthrie, J., Petty, R., Yongvanich, K. and Ricceri, F. (2004), "Using content analysis as a research method to inquire into intellectual capital reporting", Journal of Intellectual Capital, Vol. 5 No. 2, pp. 282-293.

Guthrie, J. and Abeysekera, J. (2006), "Content analysis of social, environmental reporting: What is new? ", Journal of Human Resource Costing \& Accounting, Vol. 10 No. 2, pp. 114-126.

Haynes, K. and Fearfull, A. (2008), "Exploring ourselves", Pacific Accounting Review, Vol. 20 No. 2, pp. 185-204.

Hooks, K.L.(1992), "Gender effects and labor supply in public accounting: an agenda of research issues", Accounting, Organizations and Society, Vol. 17 Nos. 3/4, pp. 343-366.

Kim, S.N. (2004), Racialized gendering of the accountancy profession: toward an understanding of Chinese women's experiences in accountancy in New Zealand, Critical Perspectives on Accounting, Vol. 15, pp. 400-427.

Kirkham, L. and Loft, A. (1993), "Gender and the construction of the professional accountant", Accounting, Organizations and Society, Vol. 18 No. 6, pp. 507-558.

Komori, N. (2008), "Toward the feminization of accounting practice: lessons from the experiences of Japanese women in the accounting profession", Accounting, Auditing \& Accountability Journal, Vol. 21 No. 4, pp. 507-538.

Lehman, C. (1992), "Fe[min]ists' account: introduction", Accounting, Auditing \& Accountability Journal, Vol. 5 No. 3, pp. 4-15.

McNicholas, P., Humphries, M. and Gallhofer, S. (2004), “Maintaining the empire: Maori women's experiences in the accountancy profession", Critical Perspectives on Accounting, Vol. 15, pp. 57-93.

Miur (2015), "Ufficio di statistica”, available at: http://statistica.miur.it/ (accessed 15 March 2015). 
Müller, J., Castaño, C., González, A. and Palmén, R. (2011), "Policy towards gender equality in science and research", Brussels Economic Review, Vol. 54 Nos. 2/3, pp. 295-314.

Nowotny, H., Scott, P. and Gibbons, M. (2001), Re-thinking science. knowledge and the public in an age of uncertainty, Polity Press, Cambridge, England.

Oecd (2015), "Data”, available at: https://data.oecd.org/ (accessed 10 November 2015).

Parker, L.D. (2005), "Social and environmental accountability research: A view from the commentary box", Accounting, Auditing \& Accountability Journal, Vol. 18 No. 6, pp. 842-860.

Parker, L.D. (2008), "Strategic management and accounting processes: acknowledging gender", Accounting, Auditing \& Accountability Journal, Vol. 21 No. 4, pp. 611-631.

Parker, L.D (2015), “Accounting historiography: looking back to the future", Meditari Accountancy Research, Vol. 23 No. 2, pp. 142-157.

Prages (2009), "Guidelines for gender equality programmes in science", available at: http://ec.europa.eu/research/ (accessed 19 January 2015).

Rees, T. (2007), "Pushing the gender equality agenda forward in the European union", Sagaria Danowitz, M. A., Women, universities and change. Gender equality in the European union and the United States, Palgrave Macmillan, New York, NY, pp. 7-21.

Rittenhofer, I. and Gatrell, C. (2012), "Gender mainstreaming and employment in the European union: A review and analysis of theoretical and policy literatures", International Journal of Management Reviews, Vol. 14, pp. 201-216.

Samkin, G. and Schneider, A. (2014a), "The accounting academic", Meditari Accountancy Research, Vol. 22 No. 1, pp. 2-19.

Samkin, G. and Schneider, A. (2014b), "Using university websites to profile accounting academics and their research output", Meditari Accountancy Research, Vol. 22 No. 1, pp. 77-106.

Siboni, B., Nardo, M.T. and Sangiorgi, D. (2013), "Italian state university contemporary performance plans: an intellectual capital focus?", Journal Of Intellectual Capital, Vol. 14 No.3, pp. 414-430.

Sinnes, A. (2006), "Three approaches to gender equity in science education", NorDina 3, pp. 72-83.

Tan, M.G., Saglamer, G. and Celik, O.A. (2011), "Women in Science, Engineering and Technology (SET) in Mediterranean Basin", Bernardino, J and Quadrado, J.C (Eds.), WEE2011, September 27-30, 2011, SEFI Annual Conference Lisbon, Portugal, pp. 86-92.

Thane, P. (1992), “The history of the gender division of labour in Britain: reflections on 'herstory'in accounting: the first eighty years", Accounting, Organizations and Society, Vol. 17 Nos. 3/4, pp. 299-312.

UN (2010), "The World's women 2010: Trends and Statistics", Department of Economic and Social Affairs United Nation, New York, NY.

Unesco (1978), "Recommendation Concerning the International Standardisation of Statistics on Science and Technology".

Unesco (2012), "Women in Science - The gender gap in science", UIS Fact Sheet, December, N. 23. pp. 1-3.

Vagnoni, E., Fioravanti, C. and Oppi, C. (2014), "Gender diversity and governance: an explorative study of Italian universities", paper presented at the Seminar La pari rappresentazione negli organi di Ateneo. Teoria e prassi a confronto, 17 October 2014, University of Ferrara, Italy.

Walker, S. (2008), “Accounting histories of women: beyond recovery?”, Accounting, Auditing \& Accountability Journal, Vol. 21 No. 4, pp. 580-610. 
Weir, P., Leach, J., Gamble, J. and Creedy, D. (2014), "Twenty-First Century Minerva: Are there career impacts for women who receive a "Women in Science" Fellowship?", International Journal of Gender, Science and Technology, Vol. 6 No. 2, pp. 196-208.

WEF (2014), “Global Gender Gap Report”, available at: http://reports.weforum.org/ (accessed 09 November 2015).

\section{Positive Action Plans in Italian Universities: does Gender really Matter?}

Table I.

Incidence of Strategies

\begin{tabular}{l|l|l|l}
\hline Strategies & $\begin{array}{l}\text { No. of Objectives } \\
\text { (potential observations) - } \\
(\mathbf{A})\end{array}$ & $\begin{array}{l}\text { No. of Observations } \\
(\mathbf{B})\end{array}$ & Total index (B/A) \\
\hline $\begin{array}{l}\text { A - A friendly environment } \\
\text { for women }\end{array}$ & 84 & 60 & $71 \%$ \\
\hline B - Gender-aware science & 56 & 21 & $38 \%$ \\
\hline $\begin{array}{l}\text { C - Women's leadership of } \\
\text { science in a changing society }\end{array}$ & 112 & 43 & $38 \%$ \\
\hline GRAND TOTAL & $\mathbf{2 5 2}$ & $\mathbf{1 2 4}$ & $\mathbf{4 9 \%}$ \\
\hline
\end{tabular}

\section{Table II.}

Frequency of Recommendations

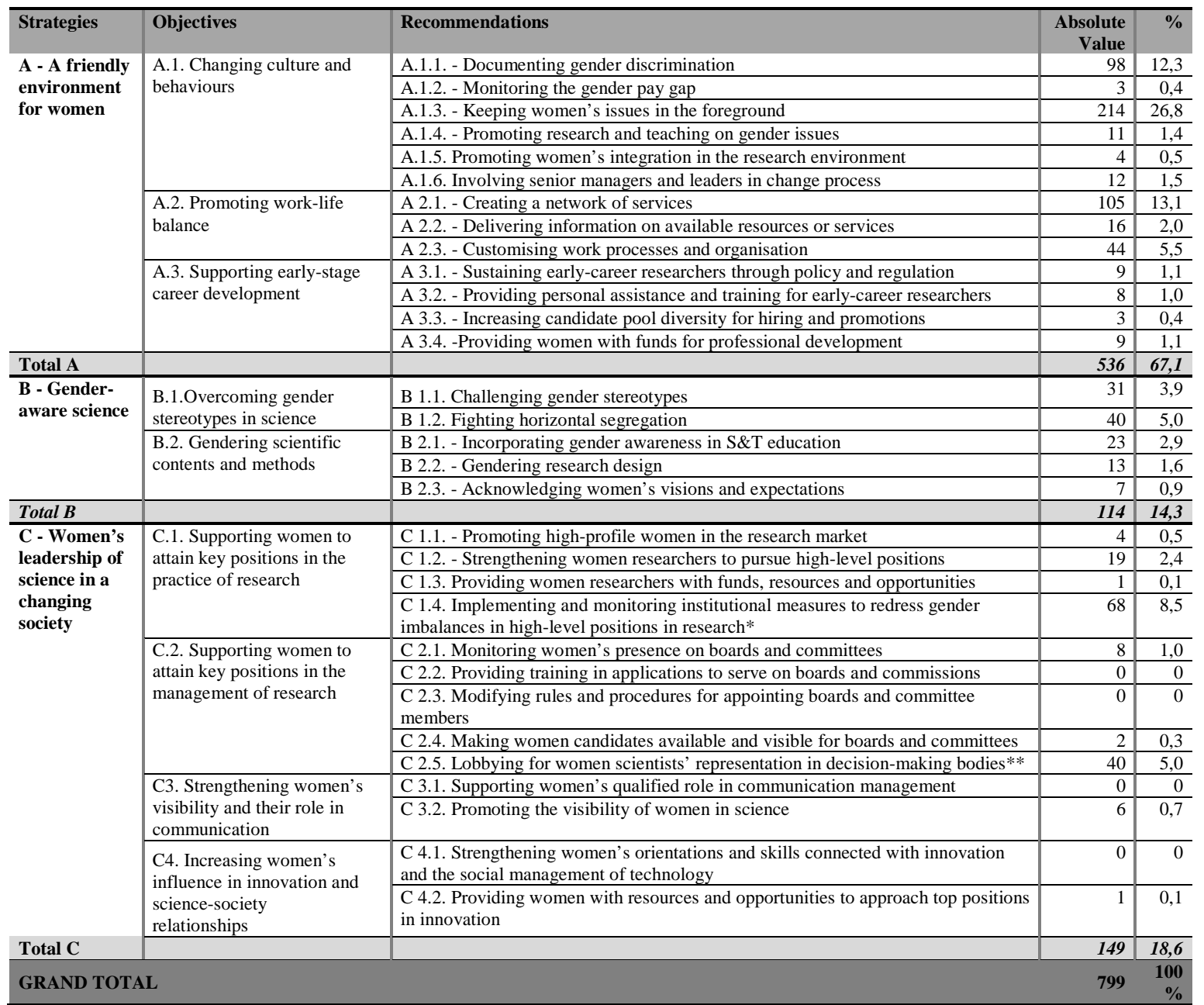

*Notably, within Recommendation C.1.4. the action to establish Guarantee Committees for Equal Opportunities, Employee Well-being and NonDiscrimination at Work has also been recorded.

**Notably, within Recommendation C.2.5. actions devoted to the promotion of networking among ISUs' and/or other public sector organisations' Guarantee Committees for Equal Opportunities, Employee Well-being and Non-Discrimination at Work have also been recorded. 


\section{Table III}

\section{Examples of Recommendations}

\begin{tabular}{|c|c|c|}
\hline Strategies & Objectives & Examples of Recommendations* \\
\hline \multirow{3}{*}{ 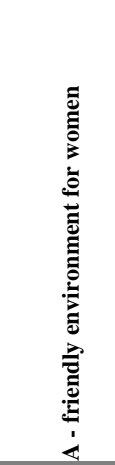 } & $\begin{array}{l}\text { A.1. Changing culture } \\
\text { and behaviours }\end{array}$ & $\begin{array}{l}\text { A.1.1 - "Systematic monitoring of working conditions of the administrative staff as } \\
\text { well as of the academics, whether structured or not, of the university ( ...) through the } \\
\text { distribution of a survey" (ID6, p. 10). } \\
\text { A.1.3 - "Posting online FAQ in the field of equal opportunities at work together with } \\
\text { their solution" (ID4, p. 8). }\end{array}$ \\
\hline & $\begin{array}{l}\text { A.2. Promoting a work- } \\
\text { life balance }\end{array}$ & $\begin{array}{l}\text { A.2.1 - "Setting up of a kindergarten and / or identification of other forms of parental } \\
\text { support" (ID20, p. 6). } \\
\text { A.2.3 - "Starting a trial of teleworking for academics and researchers, both as an } \\
\text { alternative to the use of parental leave that is different from mandatory abstention and } \\
\text { as a tool for use in the case of long and debilitating diseases" (ID18, p. 6). }\end{array}$ \\
\hline & $\begin{array}{l}\text { A.3. Supporting early- } \\
\text { stage career } \\
\text { development }\end{array}$ & $\begin{array}{l}\text { A.3.1 - "Initiatives in order to prevent leaving especially for young researchers (Ph.D. } \\
\text { students, research fellows, researchers with fixed-term contracts), through mentoring, } \\
\text { access to services of reconciliation, integration of maternity leave, recognition of the } \\
\text { time dedicated to motherhood in career competitions" (ID11, p. 18). } \\
\text { A.3.2 - "Organizing a free of charge course for active job hunting, open to female } \\
\text { students, doctoral students and researchers" (ID 10, p. 3). }\end{array}$ \\
\hline \multirow{2}{*}{ 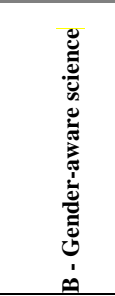 } & $\begin{array}{l}\text { B.1.Overcoming } \\
\text { gender stereotypes in } \\
\text { science }\end{array}$ & $\begin{array}{l}\text { B.1.1 - "The university is committed to adopting a neutral language from the } \\
\text { perspective of the gender in its publications and communications" (ID24, p. 13) } \\
\text { B.1.2 - "Establishment of grants of } 500 \text { euros for } 2 \text { females enrolling in Engineering } \\
\text { and } 2 \text { females enrolling in Science and Technology" (ID7, p. 7) }\end{array}$ \\
\hline & $\begin{array}{l}\text { B.2. Gendering } \\
\text { scientific contents and } \\
\text { methods }\end{array}$ & $\begin{array}{l}\text { B.2.2 - "Setting up of a documentation centre in the field of gender equality and, more } \\
\text { generally, of anti-discrimination law, (...) through a double cataloguing of volumes" } \\
\text { (ID3, p. 20). } \\
\text { B.2.2 - "Leading to a knowledge of the students and the issues of gender studies, } \\
\text { adapted to the particular characteristics of every scientific field" (ID19, p. 3). }\end{array}$ \\
\hline \multirow{4}{*}{ 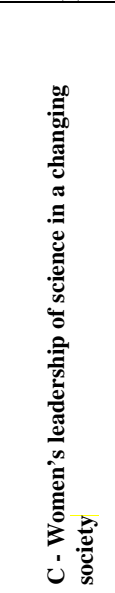 } & $\begin{array}{l}\text { C.1. Supporting women } \\
\text { to attain key positions } \\
\text { in the practice of } \\
\text { research* }\end{array}$ & $\begin{array}{l}\text { C.1.2 - "Initiatives related to the issue of female leadership, to promote the } \\
\text { empowerment of women so that both their careers were facilitated and their ability to } \\
\text { gain access to positions of leadership (self-esteem courses, networking, ability to } \\
\text { communicate assertively and to negotiate, etc.)" (ID 10, p.4). } \\
\text { C.1.4 - "Proposing and pushing specific rules that give effect to the principle according } \\
\text { to which the evaluation of the research products takes account of absences for } \\
\text { parenthood" (ID24, p. 7). }\end{array}$ \\
\hline & $\begin{array}{l}\text { C.2. Supporting women } \\
\text { to attain key positions } \\
\text { in the management of } \\
\text { research }\end{array}$ & $\begin{array}{l}\text { C.2.4 - "Promoting and supporting women candidates on boards and committees, for } \\
\text { academics and administrative staff as well as for students" (ID 22, p. 4). } \\
\text { C. } 2.5 \text { - "Making the procedures for identifying the decision-makers transparent, in } \\
\text { order to reduce the power of informal networks and increase the presence of women in } \\
\text { organisational positions" (ID11, p. 18). }\end{array}$ \\
\hline & $\begin{array}{l}\text { C.3. Strengthening } \\
\text { women's visibility and } \\
\text { their role in } \\
\text { communication }\end{array}$ & $\begin{array}{l}\text { C.3.2 - "Arranging lectures on female and male diseases and/or gender differences of } \\
\text { symptoms and treatments for men and women"(ID26, p. 20). }\end{array}$ \\
\hline & $\begin{array}{l}\text { C.4. Increasing } \\
\text { women's influence in } \\
\text { innovation and science- } \\
\text { society relationships }\end{array}$ & $\begin{array}{l}\text { C. } 4.2 \text { - "Supporting international mobility (incoming and outgoing) for those with } \\
\text { young children" (ID 11, p. 18). }\end{array}$ \\
\hline
\end{tabular}

Table IV.

Quality of disclosure

\begin{tabular}{lcc}
\hline Quality & Absolute value & \% \\
\hline Declarative & 269 & $70 \%$ \\
\hline Monetary & 0 & $0 \%$ \\
\hline Non-monetary & 103 & $27 \%$ \\
\hline Monetary and Non-Monetary & 11 & $3 \%$ \\
\hline Total & $\mathbf{3 8 3}$ & $\mathbf{1 0 0 \%}$ \\
\hline
\end{tabular}


Table V.

Stakeholder Groups

\begin{tabular}{lc|c}
\hline & Absolute value & \% \\
\hline Academics & 406 & $27 \%$ \\
\hline Researchers in training & 142 & $9 \%$ \\
\hline Administrative Staff & 466 & $31 \%$ \\
\hline Students & 249 & $17 \%$ \\
\hline $\begin{array}{l}\text { Others (such as external community, local } \\
\text { governments, etc.) }\end{array}$ & 40 & $3 \%$ \\
\hline Undeclared & 200 & $13 \%$ \\
\hline Total & & \\
\hline
\end{tabular}

